\title{
Efeitos das ações antrópicas e da mudança das marés na estabilidade do Canal da Barra do Porto de Santos
}

\section{Thiago Bezerra Correa (IC)}

\section{Resumo}

A aceleração do comércio internacional marítimo alavancou investimentos em infraestruturas no Porto de Santos, incluindo construção de terminais e dragagens de aprofundamento. Essas ações antrópicas modificam o comportamento hidráulico do estuário santista, inclusive o Prisma de Maré. Este aspecto ambiental é o volume de água responsável por carrear sedimentos do Canal da Barra, sendo um bom indicador para avaliar o impacto dessas ações na estabilidade dessa embocadura (Trecho 1), trecho responsável por cerca de $60 \%$ do volume total dragado no porto. Também foi considerado a variação das marés para quatro anos diferentes (1976, 2014, 2063 e 2113). Por meio de modelagem numérica em um modelo anteriormente calibrado e validado neste trabalho no software Mike 21 (Danish Hydraulic Institute), verificou-se que as ações antrópicas diminuem pouco o Prisma de Maré, porém o aumento da amplitude das marés compensam ou superam esse efeito, dependendo do ano analisado. Entretanto, o volume dragado anualmente no Trecho 1 tende a aumentar por conta do aumento das profundidades de manutenção do canal de navegação e da variação da profundidade de equilíbrio no Canal da Barra.

Palavras Chave: Prisma de Maré, Modelagem numérica, Porto de Santos.

\section{Introdução}

O desenvolvimento da logística marítima impulsiona a consolidação dos Hub Ports, portos concentradores capazes de absorver alto volume de cargas, transportadas por navios de grande porte, visando a uma economia de escala.

O Porto de Santos é o porto brasileiro com maior vocação para Hub Port, por estar inserido nas principais rotas transoceânicas, hinterlândia e investimento em infraestrutura.

\section{Resultados e Discussão}

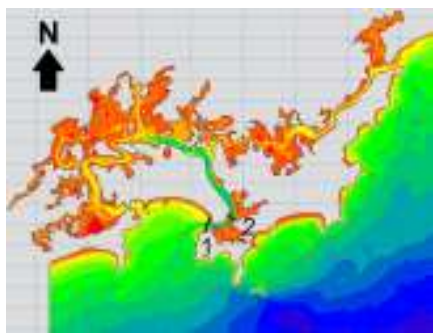

Figura 1. Modelo no software Mike 21 (seções: 1:Linha Prisma e 2:SE-1).

- Validação do Modelo Numérico

Criou-se um cenário construído, calibrado para 1976¹. A base de validação foi o Prisma de Maré $(\Omega)$ para maré unitária $(\mathrm{H}=1 \mathrm{~m})$ na seção $\mathrm{SE}-1$ da campanha da Sondotécnica ${ }^{2}$ em 1976.

Tabela 1. Validação do Modelo Numérico

\begin{tabular}{|c|c|}
\hline Cenário em 1976 & $\Omega\left(10^{6} \mathrm{~m}^{3}\right)(\mathrm{SE}-1, \mathrm{H}=1 \mathrm{~m})$ \\
\hline Sondotécnica $^{1}$ & 36,1 \\
\hline Modelo Mike 21 & 36,0 \\
\hline
\end{tabular}

- Simulações hidrodinâmicas

$\mathrm{Na}$ avaliação da estabilidade da embocadura analisou-se dois fatores na variação do Prisma $(\Omega)$ : mudança da batimetria e variação das marés.
Tabela 2. Variação do Prisma de Maré $\left(\mathrm{m}^{3}\right)$ a partir da seção 1:Linha Prisma.

\begin{tabular}{|c|c|c|c|c|c|}
\hline \multirow{2}{*}{\multicolumn{2}{|c|}{$\begin{array}{c}\text { Prisma de } \\
\text { maré }\left(10^{6} \mathrm{~m}^{3}\right)\end{array}$}} & \multicolumn{4}{|c|}{ Maré } \\
\hline & & 1976 & 2014 & 2063 & 2113 \\
\hline & Antiga & 48,0 & 46,4 & 55,9 & 69,7 \\
\hline ต & Atual & 47,6 & 45,2 & 55,1 & 69,9 \\
\hline
\end{tabular}

- Profundidade de Equilíbrio

Adotou-se a relação Área-Prisma baseada no diâmetro médio dos sedimentos ${ }^{3}$.

Tabela 3. Profundidade de Equilíbrio para Areia média $\left(\right.$ Peq $\left.=\left(1,70 \mathrm{E}-03^{\star} \Omega^{\wedge} 0,81\right) / \mathrm{L}\right)$.

\begin{tabular}{|c|c|c|c|c|c|}
\hline \multirow{2}{*}{\multicolumn{2}{|c|}{$\begin{array}{c}\text { Prof. } \\
\text { Equilíbr. (m) }\end{array}$}} & \multicolumn{4}{|c|}{ Maré } \\
\hline & & 1976 & 2014 & 2063 & 2113 \\
\hline \multirow[b]{2}{*}{0} & Antiga & 7,50 & 7,30 & 8,48 & 10,15 \\
\hline & Atual & 7,45 & 7,14 & 8,39 & 10,17 \\
\hline
\end{tabular}

\section{Conclusões}

O aumento da amplitude de maré diminui o assoreamento, enquanto 0 incremento na profundidade de navegação (de $-12 \mathrm{~m}$ para $-15 \mathrm{~m}$ ) diminui a estabilidade de forma exponencial ${ }^{4}$. Portanto, vale estudar soluções que aumentem a velocidade do fluxo no canal. Um molhe guiacorrente pode diminuir taxa de dragagem.

\section{Agradecimentos}

Ao PIBIC/CNPq pelo financiamento da pesquisa.

\footnotetext{
Souza, C. M. M. A. d. Caracterização hidrodinâmica da Baía e Estuário Santista utilizando a modelagem numérica. 2012

${ }^{2}$ Sondotécnica. Comportamento hidráulico e sedimentos do estuário santista. 1977, pág. 227-235.

${ }^{3}$ Stive, M. et al., 2010. Empirical relationship between inlet cross sectional area and tidal prism: a re-evaluation. Coastal Engineering Proceedings, 2010, 9.

${ }^{4}$ Gireli, T. Z. \& Vendrame, R. F. Aprofundamento do Porto de Santos: Uma Análise Crítica. RBRH - Revista Brasileira de Recursos Hídricos, julho, Volume 17, 2012, pág. 49-59.
} 